\title{
Quality of Life in Spanish Patients with Liver Transplant
}

\author{
M.A. Pérez-San-Gregorio ${ }^{1}$, A. Martín-Rodríguez ${ }^{1}$, J. Pérez-Bernal ${ }^{2}$ y M.D. Maldonado ${ }^{3, *}$ \\ ${ }^{I}$ Department of Personality, Evaluation and Treatment Psychological, University of Seville, Spain \\ ${ }^{2}$ University of Seville, Hospital Virgen del Rocío, Coordinator of Transplants, Spain \\ ${ }^{3}$ Department of Medical Biochemistry and Molecular Biology, Immunology Area, University of Seville Medical School, \\ Spain
}

\begin{abstract}
Background: Liver transplantation is the optimal method of treatment in patients with end-stage liver failure. Transplantation medicine has significantly progressed in the last time, but some psychology and psychosomatic problems still remain unsolved. Health-Related Quality of Life (HRQL) in liver transplant is considered a useful measure of evolutionary process of the illness.
\end{abstract}

Objective: The authors analyzed the evolution of HRQL in pre-transplant (waiting-list patients) and post-transplant (first year after liver transplant) periods of liver transplant Spanish patients.

Methods: A prospective and longitudinal study was carried out among patients who received a liver transplant from a deceased donor. They were assessed in four phases: at the time of inclusion on the transplant waiting-list, and 3, 6, and 12 months after receiving the graft. We used a structured interview and SF-36 and Euroqol-5D (EQ-5D) Health Questionnaires.

Results: The greater differences were found between pre-transplant and post-transplant stages with less well-being in the stage before the transplant. No significantly differences were observed when comparing the 3,6 and 12 months from posttransplant stage.

Conclusion: The HQRL of liver patients improved after the transplant, being appreciated a tendency to the stabilization from three months onwards. We suggest that the psychological intervention, in liver patients, should be conducted in waiting-list patients and in the first 3 months post-transplant, periods with a poor mental health (anxiety, depression, and stress by fear to the unknown thing) and a low adhesion to the treatment that can generate a smaller graft and/or patient survival.

Keywords: Health-related quality of life, Liver transplant, Pre- and post-transplant stages.

\section{INTRODUCTION}

Liver transplant has evolved from experimental treatment to standard treatment for all patients with progressive and irreversible hepatobiliary disease. Although their success has been measured by patient and graft survival, this kind of interventions can lead to very diverse conditions, ranging from recovery of "near" normality to a condition of characteristics that are similar to chronicity, with a broad array of deficits and impairments [1]. In this sense, some of the psychological complications that emerge after transplant are mood disorders, anxiety disorders, sexual disorders, fantasies about the donor, and dissatisfaction with body image [2]. Consequently, some time after transplant surgery, all of this leads patients to become more concerned about their quality of life than their longevity [3]. In this context, HealthRelated Quality of Life (HRQL) becomes more relevant; it is a multidimensional construct that includes three essential domains (physical, psychological, and social functioning), which may be affected by the disease and/or by treatment [4$6]$.

*Address correspondence to this author at the Department Medical Biochemistry and Molecular Biology, University of Seville Medical School, Avda. Sánchez Pizjuán 4, 41009. Seville, Spain; Tel: 34-954-559852;

Fax: 34-954-907048; E-mail: aibar@us.es
Most studies of this topic conclude that liver transplant leads to an improvement in patients' quality of life, which approaches but does not reach that of the general population [7-11]. For example, Pantiga et al. [12] studied HRQL in three different groups: patients with cirrhosis who presented three levels of severity (mild, moderate, and severe), transplanted patients, and healthy subjects. The results showed that the quality of life of the transplanted patients did not reach the levels of the healthy population, although it was significantly better than that of the patients with cirrhosis, especially those who were at advanced stages. Along these same lines, other studies that compare groups of sick transplant candidates, liver transplanted patients, and healthy subjects also found better functioning in the healthy people and worse in the transplant candidates. In comparison with the last group, the liver transplanted patients had fewer limitations in their psychosocial functioning, but in comparison with the control subjects, some aspects of their functioning were worse, especially in the physical and social domains [13].

Regarding the evolution of HRQL after liver transplant, investigations that establish different comparison time intervals after the graft are particularly interesting. So, for example, Bona et al. [14] found that patients' quality of life increased during the first 6 months after transplant, it de- 
creased in the 13-to-24-month time interval due to difficulties adapting to sociowork conditions, and improved between 3 and 5 years after the transplant, when the patients achieved new emotional stability. In another study in which different temporal moments were compared, Ratcliffe et al. [15] found a significant improvement in HRQL 3 months after transplant, but at subsequent follow-ups $(6,12$, and 24 months), although the perception of physical well-being continued to improve, the score referring to mood had not changed. Some investigations conclude that patients reach a degree of normality 12 months after transplant [16], whereas other studies consider that these patients have constant health problems because of the side effects of the immunosupressor treatment $[17,18]$.

On the basis of these works, we can conclude that after liver transplant, patients' HRQL is not stable, but instead different phases are observed, some better and some worse. It all depends on the temporal intervals that are compared and which are different in the diverse investigations. Given the relevance of this topic, in this research, our main goal is to analyze the evolution of HRQL in liver transplanted patients, taking into account four temporal moments: pretransplant phase (the moment the patient is included on the transplant waiting-list) and post-transplant phase (3, 6, and 12 months after receiving the graft).

\section{METHODS}

\section{Context}

This work was carried out in the University Hospital Virgen del Rocío, a hospital of reference in transplant to National level, and inside of a thematic network of transplants in all country. It is emphasized that each center, only is authorized to publish its own data and that this is the first time that is done a study of these characteristics in Spain.

\section{Subjects}

We selected a group of 27 Spanish patients (19 men and 8 women, with mean age of 51.67 years), with a cultural and economic state of middle-low, who received a first liver transplant from a person who had died at the Hospital Virgen del Rocío of Seville (Table 1). Strict confidentiality was ensured. The etiology of the different illnesses was: alcoholic cirrhosis $(30.8 \%)$, hepatitis C virus (26.9\%), hepatocarcinoma (15.3\%), hepatitis B virus (3.8\%) and others (23.2\%). The time on the waiting-list was an average of 225.08 days. All selected patients for the study possessed a severity of their liver diseases of serious in Child's Pugh, this did them patients of high priority for the transplant.

As general characteristics taken into account when selecting the patients, there were four inclusion criteria: 1) they were 18 years old or older at the moment of their inclusion on the transplant waiting-list, 2) they had sufficient cognitive capacity to complete the questionnaires, 3) they were included on the waiting-list to receive a first liver transplant (re-transplanted patients and cases with extreme urgency were excluded), and 4) they gave their written informed consent to participate in the study. Finally, they were excluded of study those patients that died previously to receive liver transplant.
Table 1. Demographic and Social Characteristics of the Patients Included in the Study

\begin{tabular}{|l|c|c|}
\hline & $\mathbf{N}=27$ & \\
\hline \hline Average age & & 51,67 \\
\hline Male & & $19(70,3 \%)$ \\
\hline Female & & $8(29,6 \%)$ \\
\hline Educational level & & Low-middle \\
\hline Marital status & & \\
\hline Married & & $6(22,2 \%)$ \\
\hline Divorced/separated & & $2(7,4 \%)$ \\
\hline Widowed & & $3(11,1 \%)$ \\
\hline Single & & $10(37 \%)$ \\
\hline Work & & $5(18,5 \%)$ \\
\hline Yes & & $12(44,4 \%)$ \\
\hline No & & \\
\hline Retired & & \\
\hline
\end{tabular}

\section{Study Design}

The liver transplanted patients were assessed in four stages: at the time of inclusion on the waiting-list for the transplant, at 3,6, and 12 months after receiving the graft. Firstly, once patients were on the waiting-list, after providing them with information about the research and clearing up all their doubts, they were asked to collaborate voluntarily and to give their written informed consent. Secondly, a structured interview was administered, in which diverse sociodemographic and clinical data were collected. Thirdly, by means of two questionnaires and at the four temporal moments of this research, we assessed HRQL. The data were collected during the interval from October 2003 until June 2006.

\section{Outcome Measures}

Structured interview: made up of three blocks: 1) general data: age, sex, weight, height, etc., 2) sociodemographic data: level of income, educational level, work situation, etc., 3) clinical data: these were requested from the patients' doctor and referred to very diverse areas such as general antecedents (consumption of tobacco and alcohol, arterial hypertension, dyslipidema, diabetes, and Chronic Obstructive Pulmonary Disease, etiology of the liver disorder (ethylic, hepatitis B, hepatitis $\mathrm{C}$, tumor, cryptogenic, hemochromatosis, etc.), date of inclusion on the waiting-list, Child-Pugh classification (mild, moderate, and severe), MELD (Model End-stage Liver Disease) classification, number of crises of acute rejection, laboratory data (hemoglobin, triglycerides, alkaline phosphatase, total bilirubin, time and rate of prothrombin, ascites, encephalopathy, etc.), type of immunosuppressor treatment for the transplant (cyclosporine, tacrolimus, sirolimus, mycophenolate mofetil, etc.), and number and duration of hospital admittances. Some clinical data were obtained directly in the first phase of the study (wait- 
ing-list) and others at the protocol follow-up performed with these patients $(3,6$, and 12 months after the graft).

SF-36 Health Survey [19]: this is made up of 36 items, each one with various response alternatives that provide a health status profile. The test explores eight dimensions: "physical functioning", "role limitations due to physical problems", "body pain", "general health", "vitality", "social functioning", "role limitations due to emotional problems", and "mental health". In each dimension, a score ranging from 0 (worse health status) to 100 (better health status) is obtained. Alonso et al. [19] studied the characteristics of reliability and validity of this test in Spanish population and found that the measures for internal reliability (Cronbach's alpha) of the different categories ranged between 0.45 and 0.94 , with a mean value of 0.78 , and always above the value of 0.70 , except for the dimension "social functioning" which did not exceed 0.45 . For test-retest reliability, the correlation coefficients ranged between 0.51 and 0.85 .

Euroqol 5-D (EQ-5D) Health Questionnaire [20]: this is a descriptive system of health status with five dimensions: "mobility", "self care", "daily living activities", "pain/discomfort", and "anxiety/depression". Each dimension has 3 items, which define three levels of severity: from 1 (better quality of life) to 3 (worse quality of life). Moreover, it includes a self-appraisal health status thermometer or analogic visual scale, the scores of which range between 0 (worst possible health status) and 100 (best possible health status). Test-retest reliability ranged between 0.86 and 0.90 [21], and regarding validity, the correlation with the SF-36 is satisfac- tory, except for the area of "psychological functioning status" [22].

\section{Ethical Considerations}

Ethical approval for the study was obtained from the ethical committee of the University Hospital Virgen del Rocío of Seville. All patients were asked to sign an informed consent form.

\section{Data Analysis}

All the analyses were performed with the SPSS statistical package for social science V16.0. In order to analyze the evolution of HRQL in the transplanted patients, we compared the different dimensions assessed by the questionnaires employed in this study at four temporal moments: moment of inclusion of patients on transplant waiting-list, and at 3, 6, and 12 months after having received the graft. For this purpose, firstly, we conducted repeated measures analysis of variance and, secondly, in the dimensions that were significant $(\mathrm{P}<0.05)$, in order to determine between which temporal moments there were differences, we performed a posteriori comparisons (pair comparisons between the levels of the time factor). In addition, to control the rate of error, both the critical levels and the confidence intervals were adjusted by means of Bonferroni's correction.

\section{RESULTS}

As can be seen in Tables $\mathbf{2}$ and $\mathbf{3}$, when comparing the phases of this study, all the dimensions that were assessed by the two questionnaires were statistically significant. The pa-

Table 2. Specific Data of the Evolution of HRQL (SF-36) in Liver Transplanted Patients. Scores Range Between 0 and 100. Higher Scores Represent Better HRQL.* $p<0.05, * * p<0.01$.

\begin{tabular}{|c|c|c|c|c|c|c|c|c|c|c|c|}
\hline \multirow{2}{*}{ SF-36 } & \multirow{2}{*}{$\begin{array}{c}\text { Phase } \\
\text { pre- } \\
\text { transplant } \\
(\mathbf{n}=\mathbf{2 7})\end{array}$} & \multicolumn{3}{|c|}{ Post-transplant phase } & \multirow{2}{*}{$p$} & \multicolumn{6}{|c|}{ Comparisons of phases $(p)$} \\
\hline & & $\begin{array}{c}3 \\
\text { months } \\
(n=27)\end{array}$ & $\begin{array}{c}6 \\
\text { months } \\
(n=27)\end{array}$ & $\begin{array}{c}12 \\
\text { months } \\
(n=27)\end{array}$ & & $\begin{array}{l}\text { Pre-3 } \\
\text { month }\end{array}$ & $\begin{array}{l}\text { Pre-6 } \\
\text { month }\end{array}$ & $\begin{array}{l}\text { Pre-12 } \\
\text { month }\end{array}$ & $\begin{array}{c}\text { 3-6 } \\
\text { months }\end{array}$ & $\begin{array}{c}\text { 3-12 } \\
\text { months }\end{array}$ & $\begin{array}{c}\text { 6-12 } \\
\text { months }\end{array}$ \\
\hline $\begin{array}{l}\text { Physical function- } \\
\text { ing }\end{array}$ & 31.66 & 62.40 & 66.48 & 73.88 & $0.000 * *$ & $0.000 * *$ & $0.000 * *$ & $0.000 * *$ & 1,000 & 0.172 & 0.262 \\
\hline $\begin{array}{l}\text { Role limitations } \\
\text { due to physical } \\
\text { problems }\end{array}$ & 9.25 & 40.55 & 45.74 & 57.68 & $0.000 * *$ & $0.004 * *$ & $0.000 * *$ & $0.000 * *$ & 1,000 & 0.449 & 1,000 \\
\hline Body pain & 65.18 & 83.98 & 78.14 & 74.81 & $0.014 *$ & $0.007 * *$ & 0.127 & 0.402 & 1,000 & 0.231 & 1,000 \\
\hline General health & 26.11 & 44.44 & 42.40 & 48.33 & $0.002 * *$ & $0.003 * *$ & $0.009 * *$ & $0.003 * *$ & 1,000 & 1,000 & 1,000 \\
\hline Vitality & 25.07 & 62.40 & 61.48 & 59.25 & $0.000 * *$ & $0.000 * *$ & $0.000 * *$ & $0.000 * *$ & 1,000 & 1,000 & 1,000 \\
\hline Social functioning & 40.74 & 72.22 & 68.05 & 69.90 & $0.000 * *$ & $0.000 * *$ & $0.004 * *$ & $0.000 * *$ & 1,000 & 1,000 & 1,000 \\
\hline $\begin{array}{l}\text { Role limitations } \\
\text { due to emotional } \\
\text { problems }\end{array}$ & 35.06 & 77.77 & 70.37 & 69.44 & $0.021 *$ & $0.009 * *$ & 0.094 & 0.071 & 1,000 & 1,000 & 1,000 \\
\hline Mental health & 50.40 & 75.40 & 73.11 & 69.62 & $0.002 * *$ & $0.001 * *$ & $0.002 * *$ & $0.027 *$ & 1,000 & 1,000 & 1,000 \\
\hline
\end{tabular}


Table 3. Specific Data of the Evolution of HRQL (EUROQOL-5D) in Liver Transplanted Patients. In the First Five Dimensions, whose Scores Range Between 1 and 3, Higher Scores Represent Worse HRQL. In the Last Dimension, whose Score Ranges Between 0 and 100, Higher Scores Represent Better HRQL. * $p<0$.05, ** $p<0.01$.

\begin{tabular}{|c|c|c|c|c|c|c|c|c|c|c|c|}
\hline \multirow{2}{*}{ EUROQOL-5D } & \multirow{2}{*}{$\begin{array}{c}\text { Phase pre- } \\
\text { transplant } \\
\quad(\mathbf{n}=27)\end{array}$} & \multicolumn{3}{|c|}{ Post-transplant phase } & \multirow{2}{*}{$p$} & \multicolumn{6}{|c|}{ Comparisons of phases $(p)$} \\
\hline & & $\begin{array}{c}3 \\
\text { months } \\
(n=27)\end{array}$ & $\begin{array}{c}6 \\
\text { months } \\
(n=27)\end{array}$ & $\begin{array}{c}12 \\
\text { months } \\
(n=27)\end{array}$ & & $\begin{array}{c}\text { Pre-3 } \\
\text { month }\end{array}$ & $\begin{array}{l}\text { Pre-6 } \\
\text { month }\end{array}$ & $\begin{array}{l}\text { Pre-12 } \\
\text { month }\end{array}$ & $\begin{array}{c}3-6 \\
\text { months }\end{array}$ & $\begin{array}{c}3-12 \\
\text { months }\end{array}$ & $\begin{array}{c}\text { 6-12 } \\
\text { months }\end{array}$ \\
\hline Mobility & 1.59 & 1.19 & 1.11 & 1.11 & $0.018^{*}$ & $0.016^{*}$ & $0.008 * *$ & $0.008 * *$ & 1,000 & 0.967 & 1,000 \\
\hline Self care & 1.41 & 1.15 & 1.04 & 1.07 & $0.004 * *$ & 0.192 & $0.004 * *$ & $0.008 * *$ & 0.498 & 1,000 & 1,000 \\
\hline Daily living activities & 2.26 & 1.67 & 1.52 & 1.56 & $0.000 * *$ & $0.007 * *$ & $0.000 * *$ & $0.000 * *$ & 1,000 & 1,000 & 1,000 \\
\hline
\end{tabular}

tients displayed less well-being in the stage before the transplant (waiting-list) in the physical, psychological, and social areas, observing an important improvement with a tendency to stabilize 3 months after receiving the transplant.

In the case of the SF-36, Fig. (1), upon comparing the pre-transplant phase with the 3-month post-transplant phase, significant improvement was observed at this second phase in the eight dimensions assessed. This same tendency was observed when comparing the pre-transplant phase with the 6- and 12-month post-transplant phases, except for the dimensions "body pain" and "role limitations due to emotional problems", where there were no significant differences. No statistically significant differences were observed in any of the dimensions assessed with the SF-36 when comparing the 3-month phase with the 6- and 12-month phases, or when comparing the latter two temporal intervals.

With regard to the Euroqol (EQ-5D), Figs. (2 and 3), when comparing the pre-transplant phase with the 3-month post-transplant interval, significant improvement was observed in all the dimensions except for the dimension "self care". Likewise, this tendency was observed in all the dimensions when comparing the pre-transplant phase with the 6-month post-transplant phase. In the comparison of the pretransplant phase with the 12-month follow-up, there was significant improvement in all the dimensions except for "anxiety-depression". There were no statistically significant differences in any of the dimensions assessed with the Euroqol when comparing the 3-month phases with the 6- and 12month phases after the transplant, or when comparing the latter two temporal moments.

\section{DISCUSSION}

After analyzing the results, we found that the patients had lower physical, psychological, and social well-being in the waiting-list phase, probably due to the fact that, at the stage immediately prior to transplant, patients usually experience
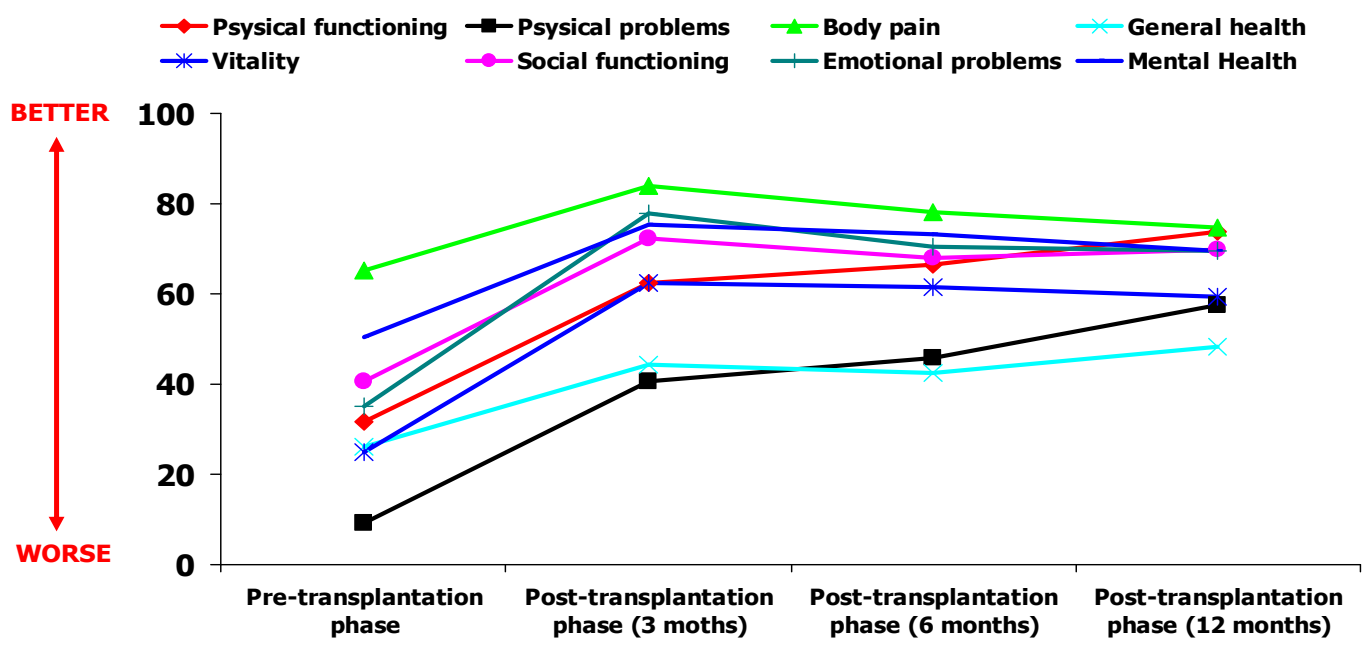

Fig. (1). Graphic representation of the evolution of HRQOL (SF-36) in liver transplanted patients. 


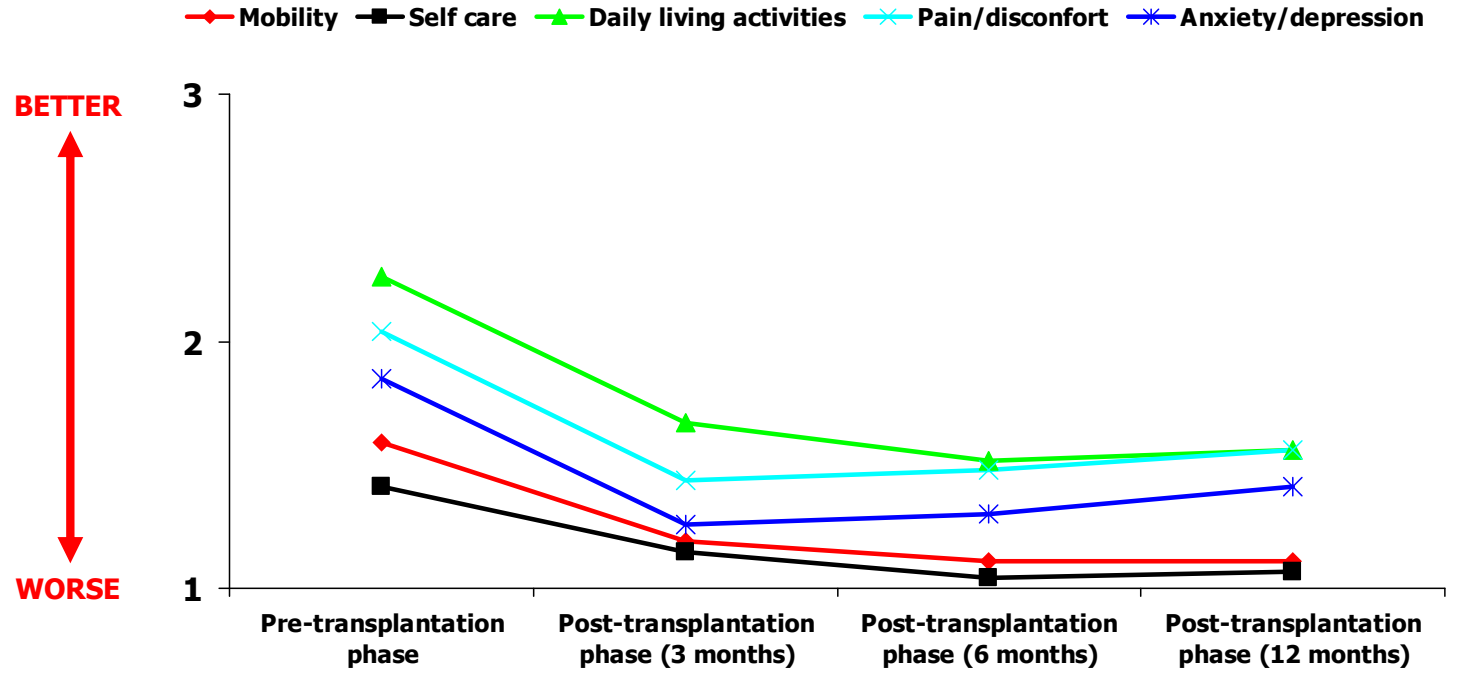

Fig. (2). Graphic representation of the evolution of HRQOL (EUROQOL-5D) in liver transplanted patients.

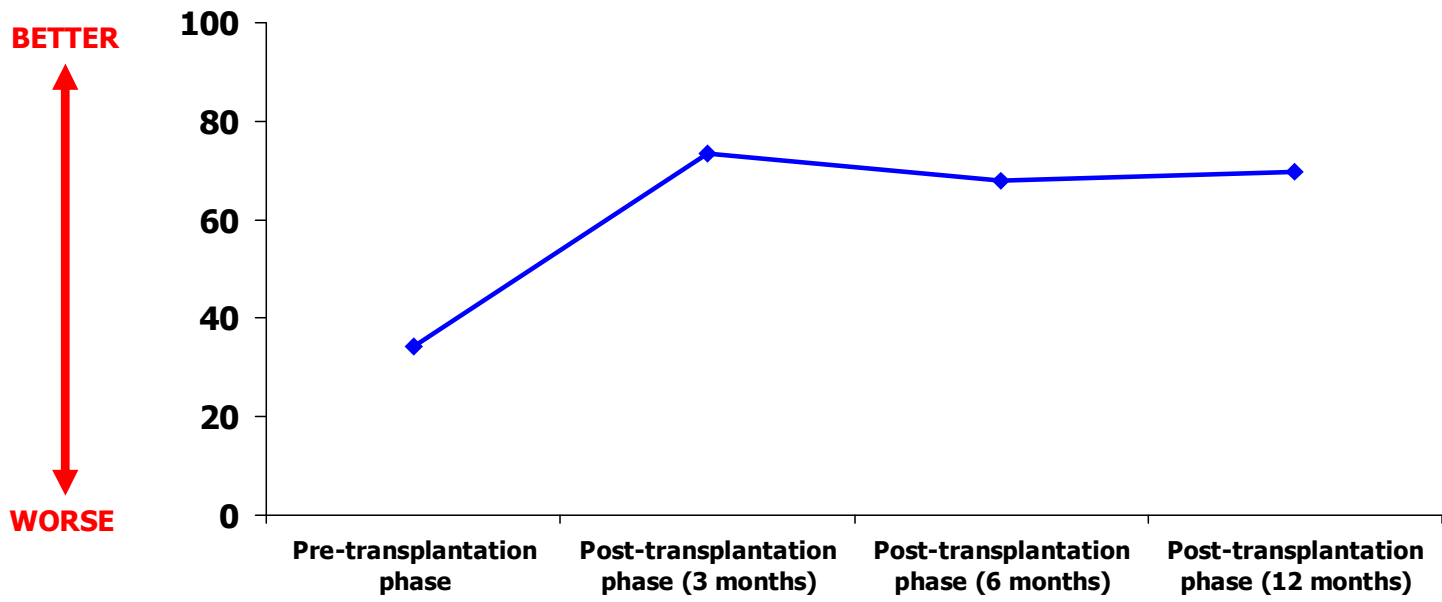

Fig. (3). Graphic representation of the evolution of "Current health" (EUROQOL-5D) in liver transplanted patients.

the typical symptoms of cirrhosis to some degree. Similar results were obtained by Burgos et al. [23], who also found that the patients displayed worse quality of life in the pretransplant phase, improving significantly after transplant, regardless of the post-transplant interval.

When comparing the pre-transplant phase (when the patient is on the waiting-list) and the post-transplant phase (3, 6, and 12 months after the transplant), patients showed a significant improvement that was more pronounced at the first post-transplant moments. Among others, the causes of their worse HRQL in the waiting-list phase lie in the fact that this stage is full of uncertainty and is associated with a high degree of morbidity and mortality, feelings of loss of freedom because patients must be located 24 hours a day, it is impossible to know how long they must wait until receiving a transplant, and the high level of anxiety caused by thinking about how they must enter an operating room to undergo a high-risk surgical intervention [24-26]. It should be taken into account that, after the transplant, the patients enjoy more physical independence because their health status improves, and this allows them to return to their daily activities and thus become integrated in their social, work, and family spheres; all of this has a positive impact on their physical, psychological, and social well-being during the diverse posttransplant phases.
When focusing on the dimensions that improved after the transplant, it must be taken into account that, in comparison with the pre-transplant phase, as time passes, there are fewer areas in which the patients presented a significant improvement. Specifically, of the 14 dimensions assessed in this study, the patients experienced an improvement at the beginning (3-month post-transplant) in 13 dimensions, subsequently (6-month post-transplant) in 12, and lastly (12month post-transplant) in 11 dimensions. This means that although HRQL improves after transplant in comparison with the pre-transplant phase, one year after surgery, three dimensions are firmly fixed: "body pain", "role limitations due to emotional problems", and "anxiety-depression". The findings of Sargent et al. [27], who also found less improvement in the psychological dimensions, point in the same direction. A possible explanation is that sometimes patients have excessively optimistic expectations about the transplant (they do not expect any medical or psychological complication), so that immediately after the transplant, these expectations are not met, especially if we take into account that all immunosupressor medications are associated with a list of adverse side effects such as general toxicity (hirsutism, gingivitis, diarrhea, osteoporosis, neurotoxicity, nephrotoxicity, arterial hypertension, diabetes mellitus, hyperlipidemia) and toxicity due to immunodepression (infections, de 
novo tumors) [28]. These sequelae are very disturbing for the patients, even to the point of limiting their improvement produced by the transplant $[29,30]$. This causes a great amount of disappointment in the transplanted patients, and some of them even think that they have exchanged their deteriorated health status for a similar status, and this has a negative impact on their mood $[15,16]$. In this context, it must be taken into account that transplanted patients usually receive a lot of information about the surgical procedure and pre-operative preparation, but little information about the adverse effects of the immunosupressor treatment [31].

However, as of 3 months, a tendency toward stabilization is observed in all the dimensions assessed, that is, whereas there are significant differences when comparing the pretransplant phase with the diverse post-transplant phases, these differences do not appear when comparing the 3-to-6month, the 3-to-12-month, and the 6-to-12-month periods. This means that, in the case of liver transplanted patients, HRQL stabilizes as of 3 months, that is, from that time on, patients' physical, psychological, and social well-being neither improves nor worsens, it simply remains stable. One could say that, as of 3 months, the patients adapt to all the circumstances involved in the transplant: they become used to the therapeutic prescriptions, they rejoin their sociowork environment, they stop fearing rejection of the organ, and they find more support from their family, because the family has recovered psychologically from the initial emotional impact of the transplant $[32,33]$. It is indicated here, that although the sample size was small, the answer was universal in all the cases, indistinctly to illness type that conducted the patients to the liver transplant.

Nevertheless, it must be remembered that liver transplantation is a complex process that requires a multidisciplinary intervention to achieve maximum HRQL in the patients, and psychological support (techniques of relaxation, training in social abilities, activities of distraction, program psychoeducational and groups of self-help) is particularly necessary in the pre-transplant phase and in the first 3 months posttransplant because that is when the patients show most physical and psychological deterioration.

\section{Limitations and Future Perspectives}

Liver transplantation not only improves length of life, but also significantly improves the quality of life of patients with end-stage liver disease. The majority of studies have reported this information, but failed to provide a longitudinal assessment that have included measures of utility of HRQL for both the pretransplantation and posttransplantation periods. In this way, would be recommendable for future researchs: A) Studying the influence that performs, in the quality of life of transplanted patients, some medical variables such as, pre-transplant (disease etiology that caused the transplant), peri- transplant (quality of the transplanted graft) and post- transplant (immunosuppressant types employed). B) Using specific instruments to evaluate the quality of life, that report of the liver illness symptoms as for example encephalopathy episodes, liver illness effects in the daily activities, concentration and memory problems, etc.

\section{ACKNOWLEDGEMENTS}

This work was supported in part by grants from the “Transplant Research Network". RETIC FIS C03/03, by Seville University and research groups: CTS-432 and CTS160 (Consejería de Innovación, Ciencia y Empresa. Junta de Andalucía. Spain).

\section{REFERENCES}

[1] Martínez G. The psychologist in the hospitable environment. Desclée de Brouwer Editions 2003: 371-93.

[2] Pérez MA, Martín A, Pérez J. Mental health of the relatives of transplanted. Psicothema 2005; 17: 651-6.

[3] Valdivieso A, Ortiz J. Generalities: Importance to measure the quality of life related to the health in the patients with liver transplant. Madrid, Editions Mayo 2006: 167-72.

[4] Littlefield C, Abbey S, Fiducia D, et al. Quality of life following transplantation of the heart, liver, and lungs. Gen Hosp Psychiatry 1996; 18: 36-47.

[5] Pérez MA, Martín A, Galán A. Psychological problems associates to the organ transplant. Int J Clin Health Psychol 2005; 5: 99-114.

[6] Aberg F, Rissanen AM, Sintonen H, Roine RP, Höckerstedt, Isoniemi H. Health-related quality of life and employment status of liver transplant patients. Liver Transpl 2009; 15: 64-72.

[7] Aadahl M, Hansen BA, Kirkegaard P, Groenvold M. Fatigue and physical function after orthotopic liver transplantation. Liver Transpl 2002; 8: 251-9.

[8] Galán A, Pérez MA, Martín A, Borda M. Quality of life of transplanted relating to other stressful medical situations lived by the pulmonary patients. Psicothema 2008; 20: 266-72.

[9] Karam V, Castaing D, Danet C, et al. Longitudinal prospective evaluation of quality of life in adult patients before and one year after liver transplantation. Liver Transpl 2003, 9: 703-11.

[10] Noma S, Hayashi A, Uheara M, et al. Psychosocial predictors of psychiatric disorders after living donor liver transplantation. Int $\mathrm{J}$ Psychiatry Clin Pract 2008; 12: 120-6.

[11] Taylor R, Franck LS, Gibson F, Hawan D. A critical review of the health-related quality of life of children and adolescents after liver transplantation. Liver Transpl 2005; 11: 51-60.

[12] Pantiga C, López L, Pérez M, et al. Quality of life in cirrhotic patients and liver transplant recipients. Psicothema 2005; 17: 1437.

[13] O'Carroll RE, Turner F, Flatley K, McGregor LM, Hayes PC. Functional outcome following liver transplantation. A pilot study. Psychology. Health Med 2008; 13: 239-48.

[14] Bona N, Ponton P, Herman M, et al. The impact of liver disease and medical complications on quality of life and psychological distress before and after liver transplantation. J Hepatol 2000; 33: 60915.

[15] Ratcliffe J, Longworth L, Young T, Bryan S, Burroughs A, Buxton M. Assessing health-related quality of life pre- and post-liver transplantation: A prospective multicenter study. Liver Transpl 2002; 8: 263-70.

[16] Dudley T, Chaplin D, Clifford C, Mutimer DJ. Quality of life after liver transplantation for hepatitis C infection. Qual Life Res 2007; 16: 1299-308.

[17] Casanovas T, Jane L. Quality of life and recovery after the liver transplant: Current transplants in University Hospital Virgen del Rocío of Seville. Spain 2006: 125-9.

[18] Holzner B, Kemmler G, Kopp M, et al. Preoperative expectations and postoperative quality of life in liver transplant survivors. Arch Phys Med Rehabil 2000; 82: 73-79.

[19] Alonso J, Prieto L, Antó JM. Spanish version of SF-36 Health Survey. An instrument to measure of the clinical results. Clinical Med 1995; 104: 771-6.

[20] Badía X, Roset M, Montserrat S, Herdman M, Segura A. Spanish version of euroqol: description and applications. Clin Med 1999; 112: 79-86.

[21] Van-Agt HM, Essinck-Bot ML, Krabbe PF. Test-retest reliability of health state valuations collected with the euroqol questionnaire. Soc Sci Med 1994; 39: 1537-44.

[22] Dorman PJ, Dennis M, Sandercock P. How do scores on the Euroqol relate to scores on the SF-36 after stroke? Stroke 1999; 30: 2146-51. 
[23] Burgos VA, Amador A, Ballesteros BP. Quality of life in patients with liver transplant. Universitas Psychologica 2007; 6: 383-97.

[24] Brown J, Sorrell JH, McClaren J, Creswell JW. Waiting for a liver transplant. Qual Health Res 2006; 16: 119-36.

[25] Díaz R, Pérez MA, Pérez J, Gallego A, Correa E. Psychological aspects of the patients included in waiting list for liver transplant. Current transplants in University Hospital Virgen del Rocío of Seville. Spain 2005: 163-7.

[26] Goetmann L, Klaghofer R, Wagner-Huber R, et al. Psychosocial vulnerability predicts psychosocial outcome after an organ transplant: results of a prospective study with lung, liver, and bonemarrow patients. J Psychosom Res 2007; 62: 93-100.

[27] Sargent S, Wainwright SP. Quality of life following emergency liver transplantation for acute liver failure. Nurs Crit Care 2006; 11: $168-76$.
[28] Berenguer M. Immediate postoperative care in patient of liver transplanted: Current transplants in University Hospital Virgen del Rocío of Seville. Spain 2008: 478-80.

[29] Ortega F. Measurement slants of the Quality of Life Related to the Health in the patients transplanted. Barcelona, Editions Mayo 2006 : 29-32.

[30] Tanikella R, Kawut SM, Brown RS, et al. Health-Related Quality of life and survival in liver transplant candidates. Liver Transpl 2010; 16: 238-45.

[31] Marcen R, Fernández AM. Quality of Life and immunosuppressant. Barcelona, Spain. Editions Mayo 2006: 83-7.

[32] Pérez MA, Martín A, Asián E, Pérez J. Symptoms of anxiety and depression in liver-transplant patients. Spanish Act Psychiatry 2004; 32: 222-6.

[33] Pérez MA, Martín A, Galán A, Blanco A. Quality of life in the health: Some investigations in the hospitable environment. Colomb J Psychol 2005; 14: 64-72.

Received: March 16, 2010

Revised: June 09, 2010

Accepted: June 17, 2010

(C) Pérez-San-Gregorio et al.; Licensee Bentham Open.

This is an open access article licensed under the terms of the Creative Commons Attribution Non-Commercial License (http://creativecommons.org/licenses/ by-nc/3.0/) which permits unrestricted, non-commercial use, distribution and reproduction in any medium, provided the work is properly cited. 